\title{
Why Canadians cycle more than Americans: A comparative analysis of bicycling trends and policies
}

\author{
John Pucher*, Ralph Buehler \\ Institute of Transport and Logistics Studies, University of Sydney, Newtown NSW 2006, Australia; Bloustein School of Planning and Public Policy, \\ Rutgers University, 33 Livingston Avenue, Room 363, New Brunswick, NJ 08901, USA
}

Received 26 May 2005; received in revised form 21 October 2005; accepted 1 November 2005

\begin{abstract}
In spite of their colder climate, Canadians cycle about three times more than Americans. The main reasons for this difference are Canada's higher urban densities and mixed-use development, shorter trip distances, lower incomes, higher costs of owning, driving and parking a car, safer cycling conditions, and more extensive cycling infrastructure and training programs. Most of these factors result from differences between Canada and the United States in their transport and land-use policies, and not from intrinsic differences in history, culture or resource availability. That is good news, since it suggests the possibility of significantly increasing cycling levels in the United States by adopting some of the Canadian policies that have so effectively promoted cycling and enhanced its safety.
\end{abstract}

(C) 2005 Published by Elsevier Ltd.

\section{Introduction}

One might assume that the much colder climate in Canada would deter cycling and thus lead to a lower bike share of urban travel in Canada than in the United States. As documented in this article, the reverse is true. In fact, cycling levels are considerably higher in Canadian cities. Even controlling for population size, Canadian metropolitan areas have bike shares of work trips about three times higher than American metropolitan areas. Just as a cool climate does not prevent cycling, a warm climate does not necessarily assure it. For example, the Yukon Territory-roughly the same latitude as Alaska-has a bike share of work trips more than twice as high as California's (2.0 vs. $0.8 \%$ ) and more than three times as high as Florida's $(0.6 \%)$.

Clearly, there must be other factors at work in Canada that offset the disadvantages of climate. It seems likely that differences in transport and land use policies play an important role in explaining the higher share of bike trips in Canada. To some extent, they may be the same policy differences that explain higher levels of transit use and walking in Canada. Several studies have found that higher densities and mixed-use development in Canadian cities promote greater transit use

\footnotetext{
* Corresponding author. Tel.: +1 732932 3822x722; fax: +1 7229322253 .

E-mail address: pucher@ rci.rutgers.edu (J. Pucher).
}

0967-070X/\$ - see front matter (c) 2005 Published by Elsevier Ltd. doi:10.1016/j.tranpol.2005.11.001 there, while the lower densities and single-use zoning in most American cities encourage car use (Cervero, 1986 and 1998; Filion et al., 2004; Goldberg and Mercer, 1986; Miron, 2003; Newman and Kenworthy, 1999; Pucher, 1994; Pucher and Lefevre, 1996; Transportation Research Board, 2001). Higher densities and mixed land uses probably encourage bike use as well, since trips tend to be shorter in compact, mixed-use environments. The much lower levels of car ownership in Canada might also encourage cycling — just as they encourage transit use. Moreover, car parking in Canada tends to be less available and more expensive than in the United States. Finally, the greater availability of transit services in Canada may complement bike use by serving those trips too long to cycle, thus facilitating a less car-dependent lifestyle.

In addition, however, both countries have government policies and programs directly targeted at bicycling. Most Canadian cities appear to have more extensive cycling networks, bike parking, and cycling education and training than most American cities. Cycling safety and promotion campaigns also differ. Clearly, such differences in bicycling policies are obvious candidates for explaining cycling levels.

This article examines a range of possible causes of the higher incidence of cycling in Canada compared to the United States. While previous studies have analyzed differences in land use, car dependence, and transit use in Canada and the United States (e.g. Transportation Research Board, 2001), none has dealt specifically with cycling. Especially given the stated goal of U.S. Department of Transportation (2004a) to double the bike share of urban travel in American cities, it makes sense 
to examine how Canadian cities have achieved their higher levels of cycling. No other country is as close to the United States in culture, lifestyle, democratic traditions, standard of living, historical development, and resource availability. Those similarities increase the likelihood that successful policies in Canada would be adaptable for use in American cities as well.

\section{Levels of cycling in Canada and the United States}

The Canadian and American Censuses are the only fully comparable sources of nationwide data on cycling levels in the two countries, but they only report on bike trips to work. The Canadian Census has reported on bicycling for the work trip since 1996. It shows an increase in the bike share of work trips in Canada from $1.1 \%$ in 1996 to $1.2 \%$ in 2001. Over the same period, the total number of bike trips increased by $18.5 \%$, almost twice as fast as work trips by all other modes (10.3\%) (Statistics Canada, 2003). The American Census has reported on cycling to work since 1980 . The bike share of work trips in the United States fell from $0.5 \%$ in 1980 to $0.4 \%$ in both 1990 and 2000 (Pucher and Renne, 2004). Thus, the overall bike share of work trips is currently three times higher in Canada than in USA (1.2 vs. $0.4 \%){ }^{1}$

As shown in Table 1, Canadians also make higher shares of their work trips by walking and public transit, more than twice the percentages in USA (6.6 vs. $2.9 \%$ for walking and 10.5 vs. $4.7 \%$ for transit). Thus, all three of the main alternatives to car use are much more heavily relied on in Canada, suggesting that there might be some common factor that discourages car use in Canada, or encourages use of alternative modes.

All available studies indicate that the bike share of nonwork trips is higher than for work trips, so both the Canadian and American Census data understate total levels of cycling. The Nationwide Personal Transportation Studies (NPTS) of 1990 and 1995 and the National Household Travel Survey (NHTS) of 2001 report on cycling in the United States for all trip purposes, both work trips and non-work trips. Those surveys report a higher bike modal share than for work trips alone, and they indicate an increasing bike share from 1990 to $1995(0.7-0.9 \%)$ but then a decrease to $0.8 \%$ in 2001 (U.S. Department of Transportation, 2004a). Unfortunately, Canada has no similar nationwide travel survey that would enable a comparison of bicycling for all trip purposes. The only Canadian surveys that report on total travel, including nonwork trips, are limited to a few large cities, but they also report considerably higher bike mode shares than for work trips (Pucher and Buehler, 2005). Such city-based travel surveys in Canada vary in design, methodology, and timing, and are not even fully comparable with other Canadian cities let alone with the overall American averages from the NPTS and NHTS. Thus, in our cross-national data analysis, we are forced to rely on the work trip data supplied by the two national Censuses.

\footnotetext{
${ }^{1}$ A sample $t$-test of the bike mode shares in Canada and USA clearly indicated that the difference is statistically significant at the $99 \%$ level.
}

Table 1

Modal share for the worktrip in Canada and USA, 2000/2001

\begin{tabular}{lcc}
\hline Transport mode & United States $(\%)$ & Canada $(\%)$ \\
\hline Auto & 87.9 & 80.7 \\
Transit & 4.7 & 10.5 \\
Bicycle & 0.4 & 1.2 \\
Walk & 2.9 & 6.6 \\
Other & 4.1 & 1.0 \\
Total & 100.0 & 100.0
\end{tabular}

Source: Statistics Canada (2003); U.S. Census Bureau (2003).

The map of North America in Fig. 1 highlights differences between the 50 USA states (and District of Columbia) and the 13 Canadian provinces and territories in levels of cycling to work. Clearly, there is great variation within each country as well. In Canada, the bike share of work trips ranges from a low of $0.1 \%$ in Newfoundland and Nunavut to a high of $2.0 \%$ in British Columbia and Yukon Territory. In the United States, the bike share ranges from a low of $0.1 \%$ in Georgia, Alabama, Mississippi, Arkansas, Missouri, and West Virginia to highs of $1.2 \%$ in the District of Columbia and $1.1 \%$ in Oregon. In general, western states and provinces appear to have higher cycling levels than those in the east, with cycling being especially low in the southeastern USA. Perhaps most amazing, as noted earlier, is the high level of cycling even in Yukon $(2.0 \%)$ and Northwest territories (1.6\%), two of the coldest and northernmost provinces of Canada.

Table 2 disaggregates the bike share information to individual metropolitan areas. All 27 Metropolitan Statistical Areas (MSAs) for Canada are shown in the table, but it was not feasible to show all 362 USA MSAs. Thus, for the United States, we show the average bike modal share for the work trip within each MSA population size category, as well as the range of values. As Table 2 clearly shows, there is much variation even among each country's MSAs in the same size category. Overall, however, Canadian MSAs have much higher bike shares of work trips. Most of the MSA population size categories indicate roughly the same 3:1 ratio of Canadian to American bike mode shares as reported above for the two countries as a whole (including rural areas). The ratio increases to $6: 1$, however, in the 1-2 million population category ( $1.9 \mathrm{vs}$. $0.3 \%$ ) and $4: 1$ in the $0.5-1$ million category (1.3 vs. 0.3 ).

\section{Factors influencing cycling levels}

There are many possible reasons why Canada has a higher bike share of urban trips than the United States. In the remainder of this article, we examine a range of factors, including cycling safety, land use patterns, car ownership rates, costs of car use, per capita income, climate, and cultural differences. We present evidence of Canadian-American differences in these factors, discuss their likely impacts on cycling, and then use multiple regression analysis to explore the relative importance of each factor. The concluding section offers some possible lessons for raising cycling levels in both countries. 


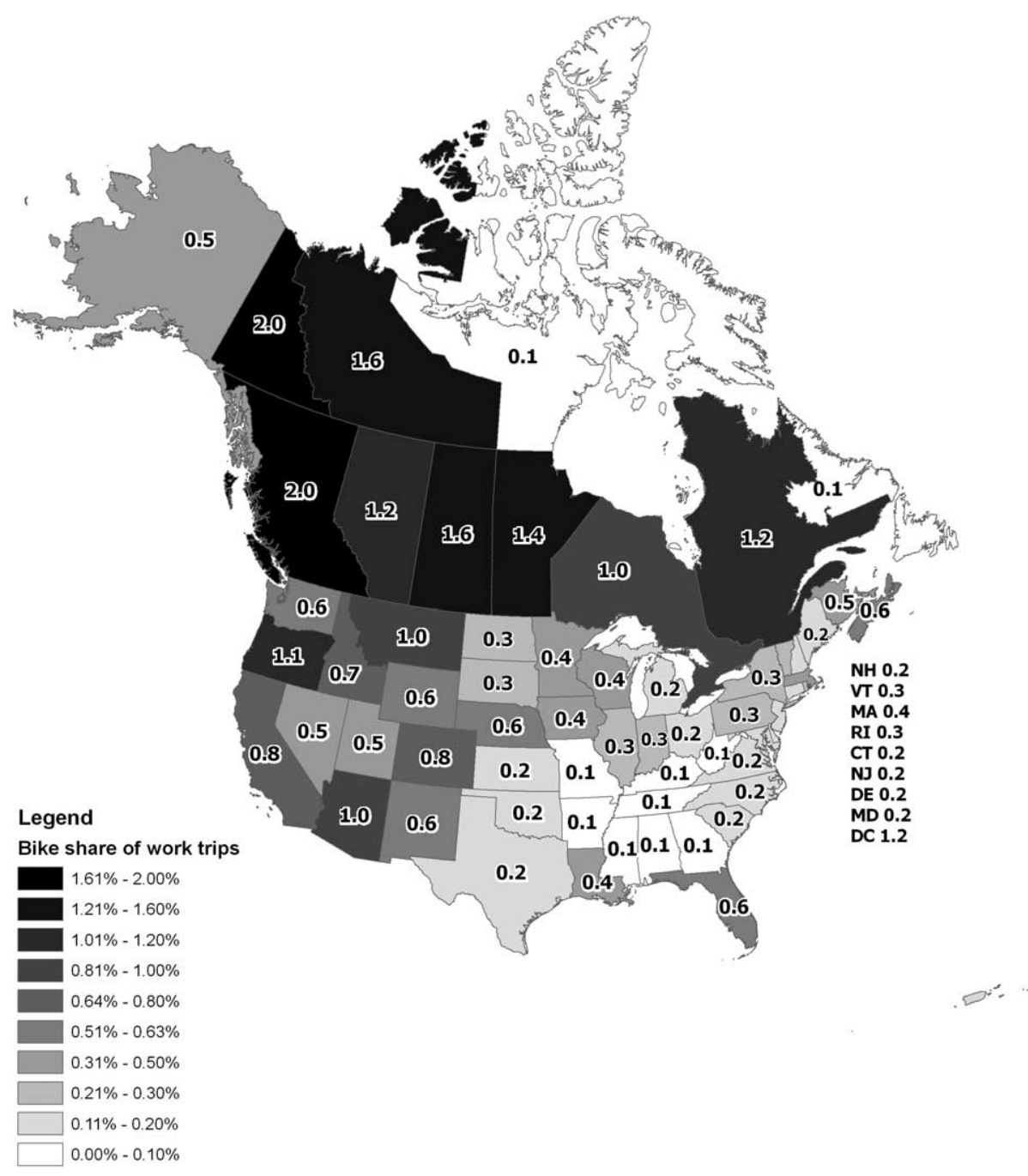

Fig. 1. Variation among American States and Canadian provinces in bike share of work trips, 2000/2001. Sources: US Bureau of the Census (2002) and Statistics Canada (2003).

\subsection{Cycling safety}

One obvious factor that can discourage cycling is the risk of death and injury in traffic crashes. Fig. 2 suggests considerably greater progress in Canada in reducing cycling fatalities than in the United States, with a $45 \%$ reduction in fatalities since 1988 , compared to a $25 \%$ reduction in USA. In contrast, Fig. 3 shows almost identical downward trends in cycling injuries, with roughly a $40 \%$ reduction in both countries. ${ }^{2}$ Neither

\footnotetext{
${ }^{2}$ Bicycling injuries reported here only include those involving a motor vehicle on a roadway. Both U.S National Highway Traffic Safety Administration (NHTSA) and the Canadian Ministry of Health record cycling injuries based on official police reports and exclude those not involving motor vehicles. Those injury statistics vastly understate total cycling injuries in both countries. Since 2000, the Centers for Disease Control and Prevention (CDC), have estimated cycling injuries based on hospital emergency room reports. CDC injury estimates are over ten times higher than those of NHTSA, roughly half a million cycling injuries every year in the US (Pucher and Dijkstra, 2003).
}

Fig. 2 nor Fig. 3 standardize for changing levels of cycling over time, or differences in cycling levels between the two countries.

Due to the lack of comparable time-series data on cycling levels in Canada and the United States, we can only attempt a standardized comparison for the latest available year. We also include selected European countries as a basis for comparison, since cycling is generally considered safer in Europe than in North America (Pucher and Dijkstra, 2003). That impression is certainly confirmed by Fig. 4, which shows rates of cycling fatalities per 100 million $\mathrm{km}$ cycled in each country. Fatality rates range from a low of 1.03 in Denmark to a high of 5.74 in the USA. With fatality rates well under 2.0, Denmark, the Netherlands, and Sweden have the safest cycling. Canada has 2.39 cycling fatalities per 100 million $\mathrm{km}$ cycled, just about the same rate as France (2.04) and Germany (2.43). The United States has, by far, the most dangerous cycling, with a fatality rate of 5.74-almost six times as high as in Denmark, almost 
Table 2

Variation in bicycling share of work trips in US and Canadian Metropolitan areas by population size, 2000/2001

\begin{tabular}{|c|c|c|c|c|}
\hline Population size & \multicolumn{2}{|l|}{ USA } & \multicolumn{2}{|l|}{ Canada } \\
\hline \multicolumn{5}{|l|}{ 3-5 Million } \\
\hline Lowest modal share & Atlanta, GA (4112) & 0.1 & Toronto, ON (4683) & 0.8 \\
\hline Mean share & & 0.4 & & 1.1 \\
\hline \multicolumn{5}{|l|}{1 Million-2,999,999 } \\
\hline Mean share & & 0.3 & & 1.9 \\
\hline \multicolumn{5}{|l|}{$500,000-999,999$} \\
\hline \multirow[t]{4}{*}{ Highest modal share } & Tucson, AZ (844) & 1.4 & Calgary, AL (951) & 1.5 \\
\hline & & & Winnipeg, MB (671) & 1.4 \\
\hline & & & Quebec, QC (683) & 1.3 \\
\hline & & & Edmonton, AB (938) & 1.2 \\
\hline & & & Windsor, ON (308) & 1.1 \\
\hline & & & Kitchener, ON (414) & 1.1 \\
\hline & & & St. Catherines-Ni., ON (377) & 0.9 \\
\hline & & & Halifax, NS (359) & 0.9 \\
\hline Lowest modal share & Jackson, MS (441) & 0.03 & Oshawa, ON (296) & 0.5 \\
\hline Mean share & & 0.5 & & 1.5 \\
\hline \multicolumn{5}{|l|}{$100,000-249,999$} \\
\hline \multirow[t]{5}{*}{ Highest modal share } & Gainesville, FL (218) & 2.8 & Saskatoon, SK (226) & 2.5 \\
\hline & & & Kingston, ON (147) & 2.2 \\
\hline & & & Trois Rivieres, QC (138) & 1.5 \\
\hline & & & Regina, SK (193) & 1.4 \\
\hline & & & Thunder Bay, ON (122) & 1 \\
\hline
\end{tabular}

Source: Statistics Canada (2003); U.S. Census Bureau (2003).

three times as high as in Canada, and about twice the rates in Italy and the $\mathrm{UK}^{3}$

Canada's relatively high bike mode share and relatively low cycling fatality rate may be functionally related. For example,

\footnotetext{
${ }^{3}$ We used the official OECD cycling fatality statistics (International Road Traffic Accident Database) for the year 2002 as the numerator of each country's fatality rate. Estimating the $\mathrm{km}$ cycled in the denominator required use of different data sources. For European countries, the total $\mathrm{km}$ cycled was estimated by multiplying the European Union's statistics on km of cycling per capita by the population of each country in 2002. For the USA, we used data from the 2001 national household travel survey, especially cross-tabulated for the authors by the Federal Highway Administration, to derive total km cycled per year. For Canada, it was much more difficult, since there is no nationwide survey of cycling, except for work trips. As a very rough approximation, we assumed a level of per capita cycling in Canada exactly twice that in the USA, given that the only fully comparable, nationwide cycling statistics report Canadian cycling at three times the American level. That probably overstates the Canadian cycling fatality rate relative to the US rate, but it is a conservative estimate. If we had assumed three times more Canadian cycling, as the Census statistics suggest, the Canadian fatality rate would have closer to Sweden's.
}

Jacobsen (2003) analyzed a wide variety of both time-series and cross-sectional data from different countries showing that higher levels of cycling are very strongly correlated with lower levels of cycling deaths and injuries. The causation probably goes in both directions. Safer cycling encourages more people to cycle, and as more people cycle, there are more cycling facilities, more cycling training, and more consideration by motorists of cyclists, all making cycling safer.

\subsection{Urban density and trip distance}

Many studies have noted that Canada's cities are generally denser than American cities, with stronger central cities, more mixed-use development, and less suburban sprawl (Cervero, 1986 and Cervero, 1998; Filion et al., 2004; Grant, 2002; Miron, 2003; Newman and Kenworthy, 1999; Vuchic, 1999). Higher densities and mixing of land uses probably encourage more cycling, simply because trip origins and destinations are 


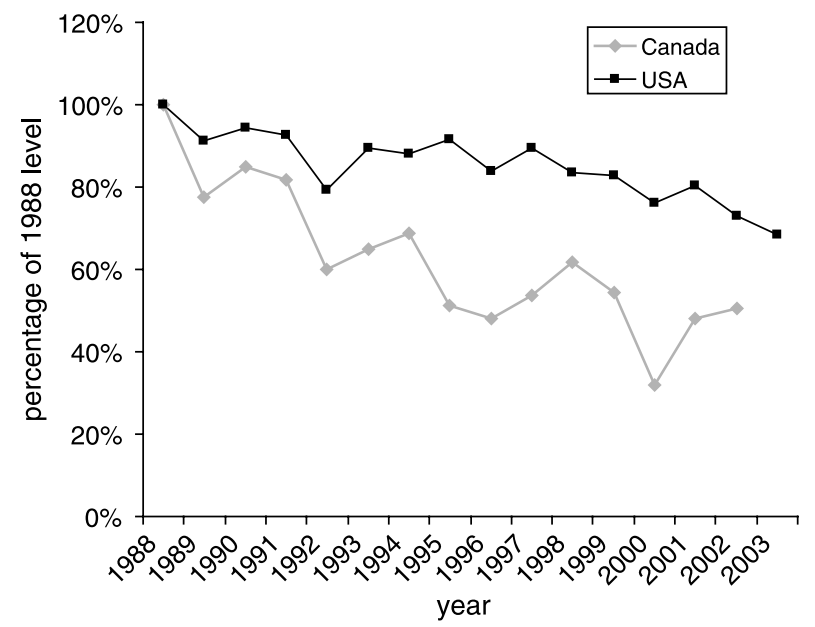

Fig. 2. Trends in bicycling fatalities in the USA and Canada, 1988-2003 (Shown as percent of 1988 fatalities). Source: Transport Canada (2004) and US Department of Transportation (2005a,b).

less spread out, so that trip distances tend to be shorter, and thus more bikeable.

Three recent quantitative studies focus specifically on comparing metropolitan densities in Canadian and American cities (Filion et al., 2004; Kenworthy, 2002; Miron, 2003). Kenworthy found that population densities of the five largest Canadian metropolitan areas in 1995 averaged 76\% higher than densities of the ten largest American metropolitan areas (2620 vs. 1490 persons per sq. km.). Similarly, job densities were $69 \%$ higher in the Canadian metropolitan areas than in the American metropolitan areas (1270 vs. 750 jobs per sq. km.). Moreover, central business districts (CBDs) in the five Canadian cities accounted for $16 \%$ of all metropolitan area jobs, compared to only $9 \%$ in the largest American metropolitan areas, indicating a stronger urban core in Canada.

Miron (2003) used 2000 and 2001 Census data and several different methodologies to compare population densities in the

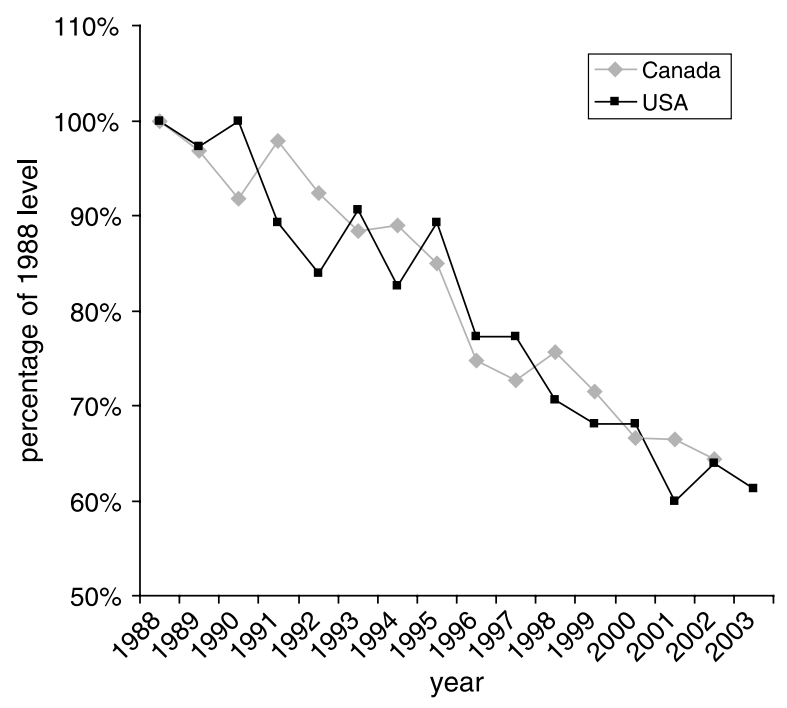

Fig. 3. Trends in bicycling injuries in USA and Canada, 1988-2003 (Shown as percent of injuries in 1988). Source: Transport Canada (2004) and US Department of Transportation (2005a,b).

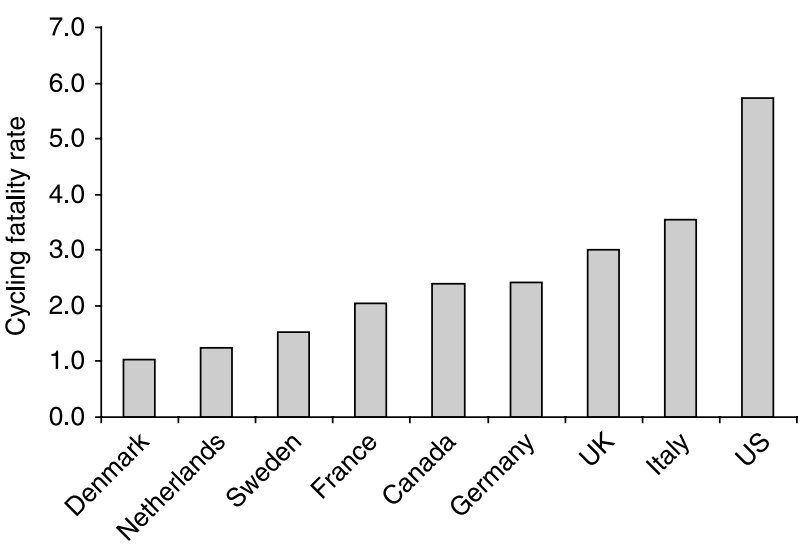

Fig. 4. Cycling fatality rates in Canada, the United States, and selected European countries, 2002. Source: Organisation for Economic Cooperation and Development (2005b); European Union (2003); and US Department of Transportation (2003 and 2005).

ten largest Canadian metropolitan areas with densities in the ten largest American metropolitan areas. The comparison is somewhat misleading, however, since the average population size of the ten largest Canadian MSAs is much smaller than the size of the ten largest American MSAs. Thus, we adjusted the Canadian average to include only the five largest MSAs, as in the Kenworthy study, and compared that with the average of the ten largest American MSAs. That modified calculation results in average Canadian metropolitan densities 50\% higher than American metropolitan densities.

Filion et al. (2004) compared average population density of the three largest Canadian metropolitan areas with the average density of twelve American metropolitan areas of comparable population size. They disaggregated the data by four rings of analysis: core area, inner city, inner suburbs, and outer suburbs. Canadian metropolitan areas have higher densities in each of the four rings, but the differences in Canadian and American densities are greatest for the three inner rings. Thus, Canadian densities averaged $127 \%$ higher in the core, $152 \%$ higher in the inner city, and $111 \%$ higher in the inner suburbs. The outer Canadian suburbs, in contrast, were estimated to be only $34 \%$ denser than their American counterparts. Filion et al. (2004) interpret the greater similarity at the suburban fringe as evidence of a possible Canadian-American convergence in development densities in recent years.

Although the three studies vary in their data and methodology, they confirm that Canadian metropolitan areas are denser than American metropolitan areas. Other studies provide extensive evidence of greater mixing of land uses in Canadian cities as well, with residential, commercial, and service functions far more likely than in the United States to be co-located and within close reach of each other (Cervero, 1986 and Cervero, 1999; Goldberg and Mercer, 1986; Grant, 2002; Newman and Kenworthy, 1999).

The expected result of higher density and mixed-use development in Canada is shorter trip distances, as strikingly confirmed by Fig. 5. Even controlling for population size category, the average length of a work trip in Canadian metropolitan areas is only about half that in the United States. 


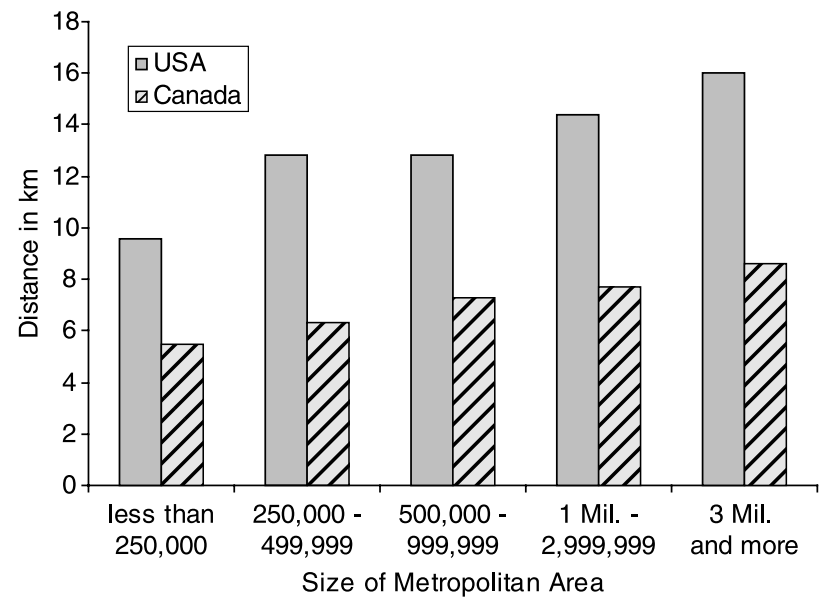

Fig. 5. Average length of work trips in American and Canadian Metropolitan areas, 2000/2001 (median trip distance). Sources: U.S. Department of Transportation (2003); Statistics Canada (2003).

For both countries, the larger the population size, the longer the average distance of the journey to work. The increased trip length, however, is far greater for American cities than for Canadian cities. For the United States, the work trip lengthens from an average of $9.6 \mathrm{~km}$ in the smallest population size category to $16.0 \mathrm{~km}$ in the largest size category. In Canada, the work trip lengthens as well, but only from 5.5 to $8.6 \mathrm{~km}$.

One would expect the dramatically shorter work trips in Canadian metropolitan areas to facilitate both walking and cycling, since these non-motorized modes are best suited to covering relatively short distances.

\subsection{Car availability and cost}

Canadians have $41 \%$ fewer cars and light trucks per capita than Americans. In 2002, there were 541 cars and light trucks per 1000 inhabitants in Canada, ranging from a low of 99 in the northernmost province of Nunavut to a high of 646 in British Columbia (Statistics Canada, 2005). In the United States, there were 762 cars and light trucks per 1000 inhabitants, ranging from a low of 388 in the District of Columbia to a high of 1160 in Wyoming (U.S. Department of Transportation, 2004b; Ward's Communications, 2004). One possible reason for the lower level of car ownership in Canada might be the lower percapita incomes there compared to the United States. Using purchasing power parities for exchange rates, the Organisation for Economic Cooperation and Development (2005a) estimates a GDP per capita of $\$ 37,000$ for the United States in 2003, 23\% higher than the $\$ 30,500$ (in US dollars) for Canada. Clearly, lower incomes and purchasing power in Canada make car ownership and use less affordable.

Not only are incomes lower in Canada, but also the overall cost of owning and operating a car are also higher. Perhaps most strikingly, gasoline prices in Canada have been about $50 \%$ higher than in the United States over the entire period 1990-2003 (see Fig. 6). The price differential is due to gasoline taxes that are twice as high in Canada as in the United States (International Energy Agency, 2005). Of course, gasoline costs

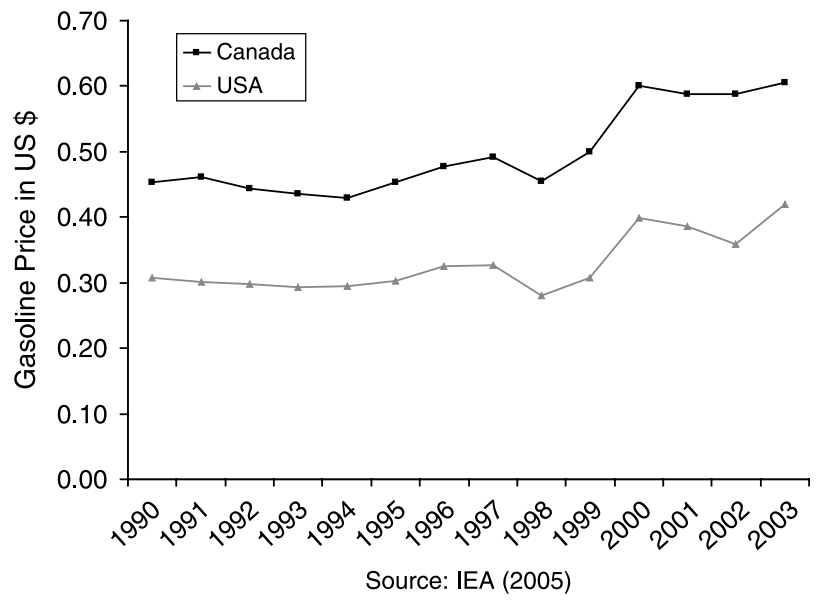

Fig. 6. Trends in gasoline prices in Canada and the US, 1990-2003 (In US Dollars per Liter).

are only a part of the overall costs of car ownership and use. The American Automobile Association (2005) and the Canadian Automobile Association (2005) use identical procedures to estimate the average costs of both owning and operating comparable models of cars. We converted the Canadian values to USA dollars and made adjustments to ensure the same mileage driven per year to estimate the total annualized cost of both owning and operating a Chevrolet Cavalier in both countries. The result was a $27 \%$ higher cost in Canada_\$8888 vs. $\$ 7002$ in USA_assuming 10,000 miles driven a year. As a percent of income, the difference in car costs is even greater: $29.1 \%$ in Canada vs. $18.6 \%$ in USA. Thus, the same car would cost almost a third of the average Canadian's income, compared to less than a fifth of the average American's income. That obviously must discourage car ownership and use in Canada to some extent, and at the same time, encourage more cycling.

\subsection{Differences in temperature and precipitation}

The slightly different timing of the Canadian and American Censuses mitigates to some extent the impact of climate on the average bike share of trips reported for the two countries. While the Canadian Census survey is conducted in May, the US. Census is taken in April. When weighted for the actual distribution of population within each province, the average Canadian temperature in May is only slightly lower than the average USA temperature in April $\left(9^{\circ} \mathrm{C}\right.$ vs. $\left.11^{\circ} \mathrm{C}\right)$ (Environment Canada, 2005; National Climatic Data Center, 2005). Temperatures are obviously higher in May than in April. Moreover, using a population-weighted average temperature for each province minimizes the impact of much colder temperatures in the northern part of each province, since most Canadians live in the southern, warmest parts of their provinces.

Nevertheless, within each country, there remain vast differences in both temperature and precipitation. Either excessively high or low temperatures can deter cycling, while precipitation of any amount, whether rain or snow, 
generally discourages cycling. Using the Census survey months for comparison, average April temperatures range from a low of $2 \mathrm{C}$ in Alaska to a high of $21 \mathrm{C}$ in both Florida and Hawaii. For Canada, the average May temperatures range from a low of $-3 \mathrm{C}$ in Nunavut and $4 \mathrm{C}$ in Yukon and Northwest Territories to highs of $15 \mathrm{C}$ in both Ontario and Quebec.

April precipitation in USA averages $8 \mathrm{~cm}$, ranging from a low of $1 \mathrm{~cm}$ in Arizona to a high of $16 \mathrm{~cm}$ in Hawaii. May precipitation in Canada averages $7 \mathrm{~cm}$ and ranges from a low of $2 \mathrm{~cm}$ in Yukon Territory to a high of $19 \mathrm{~cm}$ in Nova Scotia.

In short, average temperature and precipitation in Canada in May are roughly comparable with average temperature and precipitation in USA in April. Yet large differences in climate among the states and provinces of each country clearly have an impact on cycling levels. Thus, we include both factors as control variables in the multiple regressions presented later in this article.

\section{Bicycling policies, programs, and funding}

It is virtually certain that the factors examined above affect levels of cycling in Canada and the United States. From a planning perspective, however, it is perhaps most interesting to focus on differences in policies specifically aimed at encouraging cycling and increasing its safety. Unfortunately, it is virtually impossible to obtain national, aggregate data on the extensiveness of bikeway networks, bike parking, and cycling education and safety programs in Canada and the United States. Moreover, comprehensive national data on funding for cycling infrastructure and programs are either unavailable or incomplete. Nevertheless, there is considerable information about cycling policies, programs, and funding for selected states, provinces, and cities, and partial information on these topics at the federal level. We summarize here the available information-first on funding and planning guidelines at the federal and state/provincial government level, and then on local government policies and programs, and the actual implementation of bicycling programs in specific metropolitan areas, highlighting the most innovative and successful policies.

\subsection{Federal and state/provincial cycling policies and programs}

The federal role in funding and planning for bicycling is vastly different in Canada and the United States. Until recently, the Canadian government had virtually ignored cycling altogether. By comparison, the federal government in the United States has played a crucial role in improving cycling conditions by greatly increasing funding for cycling facilities and by requiring state departments of transportation to integrate cycling into their planning procedures and highway design.

Passage of the Intermodal Surface Transportation Efficiency Act of 1991 (ISTEA) was key to increased federal involvement in the United States (U.S. Department of Transportation, 2004a; Clarke, 2003). During the decade of the 1980s, total federal funding for bicycling and walking projects averaged only $\$ 2$ million a year. Thanks to ISTEA, annual federal funding rose to $\$ 239$ million by 1997 . The successor to ISTEA, the Transportation Equity Act for the 21st Century (TEA21), passed in 1998 and raised federal support yet further, with the annual total reaching \$413 million in 2004 (U.S. Department of Transportation, 2004c).

Potential federal funding for bicycling and walking projects, however, is far greater than the actual amounts requested by the states. Indeed, bicycling and pedestrian projects are eligible for most of the roughly $\$ 35$ billion a year the federal government gives to the states for surface transportation (Clarke, 2003). State departments of transportation have considerable discretion as to how federal funds are allocated among modes, but states have decided to use most of their federal funds for highways, devoting only a tiny percentage to cycling and walking projects. Thus, it is largely the fault of the states that subsidies to bicycling and pedestrian projects still account for only one percent of total federal transportation funding, and amount to less than $\$ 2$ per capita per year (Clarke, 2003).

The federal government not only increased funding for pedestrian and cycling projects but also turned around decades of almost complete neglect of non-motorized transportation in every aspect of transportation planning. The US Department of Transportation (1990 and 1994) set the new tone with its 1990 policy statement Moving America and its 1994 National Bicycling and Walking Study. Both documents emphasized the crucial importance of walking and cycling. The 1994 study set a specific goal of doubling the modal share of bicycling and walking in the United States. ISTEA established a legal requirement that each state, together with the metropolitan planning organizations within each state, produce a coordinated long-range, 20-year transportation plan as well as a working two-year plan (Transportation Improvement Program). Both the long-range and short-term plan must specifically consider walking and cycling needs (Clarke, 2003). Another advance of ISTEA was the requirement that every state department of transportation have a pedestrian/bicycling coordinator to facilitate non-motorized transport policies and planning within departments that are overwhelmingly focused on highways. Prompted by the passage of TEA21 in 1998, the U.S. Department of Transportation (2000) issued yet another policy statement specifically laying out design guidelines for accommodating bicyclists and pedestrians in all federallyfunded highway and transit projects.

In short, the federal government in the United States has been the leading force behind increased funding for cycling, and its fuller integration in the planning of overall transportation systems. With a few exceptions, most state departments of transportation have only reluctantly cooperated with federal requirements and policy recommendations. Many states have simply ignored certain federal requirements and recommendations. Wilkinson and Channcey (2003) assessed the degree of state compliance with federal policies. They found that only 29 states and the District of Columbia have a long-range plan or plan element for bicyclists and pedestrians, although this is a legal, statutory requirement. Moreover, only eight states have 
bike/ped plans with measurable goals. Only 25 states reported that they routinely accommodate bicyclists in their highway projects. Only 11 states currently have safe routes to school programs and only five of those come with any significant funding. Aside from providing the required $20 \%$ state and local matching funds for federally financed projects, most states have done the least possible for cyclists and pedestrians and continue to focus almost all their efforts on roads. Thus, total state funding for highways exceeded $\$ 49$ billion in 2004almost 400 times as much as the $\$ 125$ million in state funding for pedestrian and bicycling projects (U.S. Department of Transportation, 2005b, Table HF-10).

Until very recently, the Canadian government played no role whatsoever in cycling policies, programs, and funding. That results from the long-time federal policy of non-intervention in urban transportation in general, leaving that to the provinces and municipalities. Only in 2003 did Transport Canada, the federal ministry of transport, announce the new urban transportation showcase program. In a nationwide competition, eight Canadian municipalities were awarded a total of $\$ 40$ million (US $\$ 32$ million) over five years for innovative projects that would help reduce greenhouse gas emissions (GHG) from transportation sources (Transport Canada, 2003). Four of the eight funded proposals included cycling elements in their overall projects. The new federal funding was prompted by the 2002 signing of the Kyoto Protocol on climate change, which requires Canada to reduce its GHG by $6 \%$ by 2012 . While this new funding is welcome, it is a one-time program and amounts to only about $\$ 2$ million (US \$1.6 million) a year in federal cycling funds for the entire country.

At the provincial level, only Quebec has strongly supported cycling. Indeed, the provincial ministry of transport (Transports Quebec) and the province-wide organization Velo Quebec have taken the lead in planning, coordinating, and funding the province-wide network of cycling paths. The province adopted an official bicycle policy in 1995 with the goal of increasing cycling levels while enhancing safety. As part of that official policy, all provincial transport infrastructure projects must incorporate the needs of cyclists in their design. Thanks to $\$ 89$ million (US $\$ 71$ million) in funding from Transports Quebec and about $\$ 180$ million (US \$144 million) from other government agencies and municipalities, Quebec's bikeway network grew almost ten-fold from 1992 to 2004 (from 778 to almost $7000 \mathrm{~km}$ ), with even more expansion planned (Transports Quebec, 2004a and 2004b; Velo Quebec, 2003).

The only other Canadian province that has provided any support at all for cycling is British Columbia, but its efforts pale in comparison to those of Quebec, with funding averaging only $\$ 1.5$ million (US \$1.2 million) a year from 1995 to 2004. Thus, with the exception of Quebec, cycling policies, programs, and funding are almost entirely dependent on local government support.

\subsection{Local government initiatives to promote cycling}

As difficult as it is to obtain comprehensive, nationwide information on state and provincial policies and funding, it is even more difficult to obtain comparable data for hundreds of individual cities. Neither Canada nor the United States has aggregate statistics on local government cycling programs, or even a representative survey. We present in this section a brief summary of typical measures undertaken by cities in both countries, providing specific examples in a few cities. The cities included may not be fully representative, but they give some indication of what different cities are doing. Most of the information is drawn from detailed city case studies published elsewhere (League of American Bicyclists, 2005; National Center for Walking and Cycling, 2005a and 2005b; Pucher and Buehler, 2005; Pucher et al., 1999; Thunderhead Alliance and Chicagoland Bicycle Federation, 2004) but with updates and the inclusion of a few additional cities, we investigated especially for this paper.

\subsubsection{Bicycling paths, lanes, and other right of way provisions}

Few studies have even attempted to collect, standardize, and compare the extent of bicycling facilities in the United States, and no study has done this for Canada. Three studies report on the length of bike lanes and paths in selected American cities (Nelson and Allen, 1997; Dill and Carr, 2003; Thunderhead Alliance and Chicagoland Bicycle Federation, 2004). All three rely on voluntary survey responses from bicycling coordinators, and none of the samples is statistically representative of the United States as a whole. Similarly, the corresponding statistics we collected for Canadian cities are not necessarily representative, since they came from cycling coordinators in large cities. Table 3 presents our summary of the best available estimates of the length of separate cycling facilities per 100,000 persons in each of 19 American and seven Canadian cities. Somewhat similar to the modal split statistics in Table 2, the bicycling facilities statistics in Table 3 show large variation among cities within the same population size category. Cycling facilities appear to be considerably more extensive, at least on a per-capita basis, for medium-size cities than for large cities, and this pattern holds for Canada as well as the United States. Overall, the Canadian cities average almost three times as many kilometers of bike paths and lanes per capita as the American cities sampled (45.7 vs. $17.4 \mathrm{~km})$. That might be functionally related to the higher levels of cycling in Canada (both cause and effect), or it might be a statistical quirk resulting from a biased choice of sampled cities.

At any rate, statistics on bike paths and lanes are almost never entirely comparable, since the length of such bikeways says nothing about their quality, their specific design, how well they are maintained, and to what extent they are well connected to each other and to destinations people need to reach. Bike lanes can vary in type. Most are to the right of motor vehicle traffic in the same direction of travel. By comparison, almost all of Montreal's bike lanes are bi-directional, sometimes on the right hand side of the street, sometimes on the left, but separated from motor vehicles by special barriers. Toronto and a few other Canadian cities have mixed-use bike/taxi/bus lanes on downtown streets. Bike paths also vary greatly in their design, sometimes completely separated from roadways, 
Table 3

Extent of cycling facilities in selected Canadian and American cities

\begin{tabular}{|c|c|c|c|c|c|c|}
\hline \multirow[t]{2}{*}{ Population size } & \multicolumn{3}{|l|}{ USA } & \multicolumn{3}{|l|}{ Canada } \\
\hline & Metropolitan area & $\begin{array}{l}\text { Kilometres of bike } \\
\text { paths and lanes per } \\
100,000 \text { pop. }\end{array}$ & $\begin{array}{l}\text { Bike modal share } \\
(\%)\end{array}$ & Metropolitan area & $\begin{array}{l}\text { Km of bike paths } \\
\text { and lanes per } \\
100,000 \text { pop. }\end{array}$ & $\begin{array}{l}\text { Bike modal share } \\
(\%)\end{array}$ \\
\hline \multicolumn{7}{|l|}{ Over 5 million } \\
\hline & Los Angeles & 7.3 & 0.6 & & & \\
\hline & Philadelphia & 23.1 & 0.3 & & & \\
\hline & Chicago & 4.6 & 0.3 & & & \\
\hline & New York & 4.1 & 0.4 & & & \\
\hline & Average & 9.8 & 0.4 & & & \\
\hline \multicolumn{7}{|l|}{ 3-5 Million } \\
\hline & Washington DC & 14.0 & 0.3 & & & \\
\hline & Houston & 21.4 & 0.3 & Toronto & 8.7 & 0.8 \\
\hline & Boston & 3.8 & 0.6 & Montreal & 29.3 & 1.3 \\
\hline & Average & 13.1 & 0.4 & & 19.0 & 1.1 \\
\hline \multicolumn{7}{|c|}{1 Million-2,999,999 } \\
\hline & Minneapolis & 34.5 & 0.4 & & & \\
\hline & St Louis & 26.4 & 0.1 & & & \\
\hline & Seattle & 14.5 & 0.7 & Vancouver & 29.0 & 1.9 \\
\hline & Pittsburgh & 10.0 & 0.1 & Ottawa & 65.9 & 1.9 \\
\hline & Denver & 28.6 & 0.4 & & & \\
\hline & Portland & 60.9 & 0.8 & & & \\
\hline & San Francisco & 8.7 & 1.4 & & & \\
\hline & Milwaukee & 7.0 & 0.2 & & & \\
\hline & New Orleans & 3.4 & 0.6 & & & \\
\hline & Average & 21.6 & 0.5 & & 47.5 & 1.9 \\
\hline \multicolumn{7}{|l|}{ 500,000-999,999 } \\
\hline & Madison & 37.6 & 1.7 & Calgary & 68.3 & 1.5 \\
\hline & Fresno & 5.4 & 0.7 & Edmonton & 64.6 & 1.2 \\
\hline & Raleigh & 14.4 & 0.4 & Quebec & 54.0 & 1.3 \\
\hline & Average & 19.1 & 0.9 & & 62.3 & 1.3 \\
\hline National average & & 17.4 & 0.5 & & 45.7 & 1.4 \\
\hline
\end{tabular}

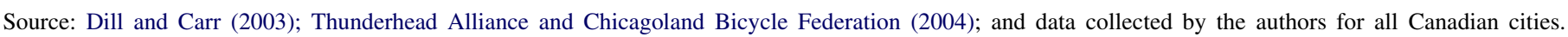

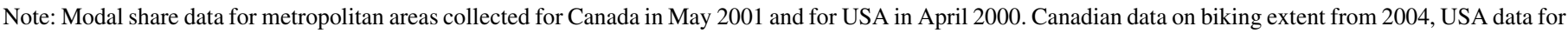
2000 .

such as off-road recreational trails, which usually permit walking, running, and in-line skating as well as cycling. Many cities also have so-called sidepaths, bike paths that closely parallel roads, with some sort of buffer between cyclists and motor vehicle traffic. Cycling on sidewalks is usually illegal but common in all cities. In Edmonton, however, over $100 \mathrm{~km}$ of sidewalks have been officially designated as mixed-use facilities, with signs and pavement markings indicating that cycling is permitted.

Statistics on the extent of bike lanes and paths understate the full extent of the cycling network, since they do not include signed bike routes on roadways or traffic-calmed residential streets, some of which can be as safe and attractive for cycling as separate facilities such as lanes and paths. Traffic calming appears to be much more extensive in Canadian cities than in American cities. For example, Vancouver, Toronto, and Calgary rely heavily on traffic-calmed neighborhood streets as essential components in their overall cycling network. We attempted to collect statistics on the exact extent of traffic calming, but very few cities have this information. Most cities have statistics on the extent of bike routes on roadways, but the actual cycling conditions of such routes vary so widely that they are not comparable among cities.

\subsubsection{Bike parking, car parking, and other policies}

Convenient, safe, and ample bike parking is obviously an inducement to cycle, just as convenient, ample free car parking is an inducement to drive. While we have considerable information on bike parking in Canadian cities, we have only fragmentary data for American cities. Most of the large Canadian cities we studied in detail require the private provision of bike parking in their zoning and building codes and make the public provision of bike parking on sidewalks and at transit stops a top priority (Pucher and Buehler, 2005). The city of Toronto, for example, has almost 15,000 of its famous post-and-ring bike racks on sidewalks, and continues to install about 1000 new racks per year. It also provides bike parking at most rail transit stations. Indeed, Toronto is reputed to have the most bikes parking of any city in North America. Ottawa has the second-most bike parking in Canada, with over 10,000 bike racks in public spaces and government offices. Chicago tops the list of bike parking among American cities, with 9200 bike racks on sidewalks, about four times as many as Seattle's 2300 and almost five times as many as New York's 1800. Unfortunately, few American cities have conducted complete inventories of bike parking, making comparisons with Canada difficult. Our overall impression from in-depth 
case studies is that most Canadian cities make a concerted effort to provide safe and convenient bike parking. With a few exceptions, the American cities we contacted did not make bike parking a high priority, and most large American cities provide less bike parking than even medium-sized cities in Canada. There are no fully comparable, comprehensive statistics for both countries, however, to substantiate that impression from selected case studies.

The more restrictive car parking policies in Canadian cities are not intended to encourage cycling, but they may have that impact, especially in cases where car parking is actually replaced by bike parking. At least three studies find considerably less parking supply for cars in Canadian cities (Cervero, 1986 and Cervero, 1998; Kenworthy 2002; Shoup, 1999). That is partly because American cities, on average, set minimum parking requirements that are three times higher than in Canadian cities (Shoup, 1999). Indeed, a few Canadian cities set maximum instead of minimum parking requirements and have deliberately reduced car parking downtown and near key transit stations to discourage car use (Cervero, 1986 and Cervero, 1999). When comparing large cities in both countries, Kenworthy (2002) found that Canadian cities had only about two-thirds as much parking per 1000 jobs as American cities (390 vs. 555 spaces per 1000 jobs).

There are many other policies that can affect cycling levels, but as with bike parking, the available data are incomplete and generally incomparable. Many cities in both Canada and the United States have specific policies to encourage integration of transit and cycling by putting bike racks on buses, allowing bikes to be taken on trains, and providing bike parking at transit stops. Several Canadian cities provide special intersection modifications that give cyclists an advance stop line as well as priority signaling, triggered either manually by push buttons or automatically by sensors in the pavement that detect bikes. Most Canadian cities and many American cities have been improving their overall bike route network, with better linkages, better signage, and clearer route designations.

Almost all large and medium-size cities in Canada offer a wide range of cycling courses for all age groups through the national cycling education program 'CAN-Bike' as well as promotional events such as bike races, bike rodeos, and cycling festivals. Many American cities-such as Seattle, Portland, and Chicago-also offer such special cycling events. Toronto has a Cycling Ambassador outreach program that sends a team of ten professionally trained cyclists into neighborhoods throughout the city to teach cycling safety and skills courses and to promote cycling in general. Several Canadian cities have detailed cycling maps available, as well as extensive websites with a wide range of up-to-date information for cyclists. Montreal offers a special cycling café-restaurant (Maison des Cyclistes) that also serves as a multi-faceted center to coordinate cycling events, provide information, promote cycling tourism, and repair bikes. An innovative program in Minneapolis is the guaranteed ride home, which offers cyclists travel vouchers worth $\$ 50$ a year to use toward bus and taxi fares in the event of an emergency or schedule conflict that prevents them from cycling back home from work. Finally, many cities in both countries have introduced police squads on bikes. Toronto has the most extensive program of those we found, with over 900 police officers trained as bike police, of which an average of 300 are on duty on any given day during the summer months. Ottawa, Vancouver, and Victoria also have large bicycle police squads. Many American cities have also introduced police on bikes, following the example of Seattle, which introduced the concept in the United States in 1987.

The preceding listing of sample measures is only intended to give a general overview of the sorts of measures undertaken to promote cycling by local governments. Since comparable data on these measures are unavailable, the multiple regression analysis that follows necessarily is limited to examining the impacts of the more quantifiable factors mentioned earlier, for which we have a solid statistical database and comparable statistics for both countries.

\section{Multiple regression analysis of factors influencing cycling levels}

Few studies have attempted to use multiple regression to examine the relative importance of factors influencing cycling levels. Baltes (1997) relied exclusively on Census data from 1990 to analyze the bike share of work trips in 284 MSAs in the United States. He did not examine any policy variables at all, but found that high urban population density, temperate climate, and a high proportion of college students were all associated with higher bike share of the work trip. Nelson and Allen (1997) explicitly included in their analysis a variable that measured the extent of separate bike lanes and paths per 100,000 population. Controlling for other factors such as climate, topography, and the percent of college students, they found a significant positive relationship between the supply of bikeways and the bike share of work trips. The difficulty of collecting information on bikeways limited the sample to only 18 cities. Dill and Carr (2003) conducted a similar analysis, using 2000 Census data for 35 cities, supplemented by additional information they collected from cycling coordinators in each city on the extent of bike lanes and paths in each city. They also find a positive relationship between bike share of work trips in American cities and the extent of their bike lanes and paths per 100,000 inhabitants. Even including factors such as gasoline price, days of rain, and state spending per capita on bicycling facilities, their regressions explain at most $30 \%$ of the total variation among the 35 cities in their bike modal shares.

While these three studies examined variation among cities or metropolitan areas in their bike share of the work trip, our regression analyzes differences among American states and Canadian provinces, yielding a total sample size of 64 , of which 59 provided complete information for inclusion in the final regression. Table 4 lists the variables used in the regression, describing each variable and noting its units of measurement and data sources. We did not include per-capita income because of its high correlation with car ownership, and also because the most important impact of income on cycling levels is probably via car ownership. Urban population density 
Table 4

Variables in the regression: units of measurement, explanation and data sources

\begin{tabular}{|c|c|c|c|}
\hline Variable & Units of measurement & Explanation & Source \\
\hline \multirow[t]{2}{*}{ Cycling share } & \multirow[t]{2}{*}{ Percent of work trips } & $\begin{array}{l}\text { US: modal share of bike trips for journey to work } \\
\text { in April } 2000 .\end{array}$ & US Census (2005) \\
\hline & & $\begin{array}{l}\text { Canada: modal share of bike trips for journey to } \\
\text { work in May } 2001 .\end{array}$ & Statistics Canada (2005) \\
\hline \multirow[t]{2}{*}{ Precipitation } & \multirow[t]{2}{*}{ Centimeter } & $\begin{array}{l}\text { US: area-weighted monthly normal precipitation } \\
\text { in April (average for 1971-2000). }\end{array}$ & $\begin{array}{l}\text { US National Climatic Data Center (NCDC) } \\
(2005)\end{array}$ \\
\hline & & $\begin{array}{l}\text { Canada: population-weighted monthly average } \\
\text { precipitation for May } 2001 .\end{array}$ & Environment Canada (2005) \\
\hline \multirow[t]{2}{*}{ Temperature } & \multirow[t]{2}{*}{ Degrees celsius } & $\begin{array}{l}\text { US: area-weighted monthly normal temperature in } \\
\text { April (average 1971-2000). }\end{array}$ & $\begin{array}{l}\text { US National Climatic Data Center (NCDC) } \\
(2005)\end{array}$ \\
\hline & & $\begin{array}{l}\text { Canada: population-weighted monthly average } \\
\text { temperature for May } 2001 .\end{array}$ & Environment Canada (2005) \\
\hline \multirow[t]{2}{*}{ Gas price } & \multirow[t]{2}{*}{ US dollars per liter } & $\begin{array}{l}\text { US: average gasoline price in each state in April } \\
2000 .\end{array}$ & $\begin{array}{l}\text { Energy Information Administration (EIA) (2000), } \\
\text { US Department of Transportation (2005) }\end{array}$ \\
\hline & & $\begin{array}{l}\text { Canada: average population-weighted gasoline } \\
\text { price in each province for May } 2001 .\end{array}$ & Canadian Petroleum Products Institute (2001) \\
\hline \multirow[t]{2}{*}{ Car availability } & \multirow[t]{2}{*}{ Cars per inhabitant } & $\begin{array}{l}\text { Canada: number of cars and light trucks per } \\
\text { person for each province. }\end{array}$ & US Department of Transportation (2005a) \\
\hline & & & Statistics Canada (2005) \\
\hline \multirow[t]{2}{*}{$\begin{array}{l}\text { Median distance of work } \\
\text { trip }\end{array}$} & \multirow[t]{2}{*}{ Kilometer } & $\begin{array}{l}\text { US: population-weighted median commuting } \\
\text { distance by city size category. }\end{array}$ & US Department of Transportation (2005a) \\
\hline & & $\begin{array}{l}\text { Canada: population-weighted median commuting } \\
\text { distance per province. }\end{array}$ & Statistics Canada (2005) \\
\hline US-Canada dummy & $1 / 0$ & $\begin{array}{l}\text { US: one for each state } \\
\text { Canada: } 0 \text { for each province }\end{array}$ & \\
\hline \multirow[t]{2}{*}{ Cycling fatality rate } & \multirow[t]{2}{*}{$\begin{array}{l}\text { Fatality rate per } 100,000 \\
\text { people cycling }\end{array}$} & $\begin{array}{l}\text { US: number of cyclist fatalities per } 100,000 \\
\text { cyclists in each state. }\end{array}$ & $\begin{array}{l}\text { US Department of Transportation }(2005 a, b), \text { US } \\
\text { Census (2005) }\end{array}$ \\
\hline & & $\begin{array}{l}\text { Canada: number of cyclist fatalities per } 100,000 \\
\text { cyclists in each province. } \\
\text { Calculated as total cycling fatalities divided by } \\
\text { total population weighted by the modal share of } \\
\text { cycling in each state or province. }\end{array}$ & $\begin{array}{l}\text { Transport Canada (2004); Statistics Canada } \\
(2005)\end{array}$ \\
\hline
\end{tabular}

is not in the equation because it was not feasible to calculate it in a meaningful way at the state and provincial level. Moreover, the trip distance variable captures the most important aspect of density's impact on travel behavior.

Table 5 shows the statistical distributions of each variable as well as the simple, bivariate correlations between the dependent variable (bike share of work trips) and each of the explanatory variables. It is noteworthy that all of the explanatory variables have the expected signs, and all except temperature are statistically significant at the $99 \%$ level. Thus, high gasoline prices are associated with higher cycling levels, while car ownership, precipitation, cycling fatality rate, median trip distance, and location in the United States are all associated with lower cycling rates.

Table 6 shows the results of the multiple regression-one equation with the US-Canadian dummy variable, and one without it. The adjusted R Square (controlling for degrees of freedom) is 0.596 for the first equation, and 0.599 for the second, suggesting that both equations explain about $60 \%$ of the variation among the 59 states and provinces for which data on all the variables were available. Both equations are statistically significant at the $95 \%$ level. In contrast to the bivariate correlations shown in Table 5 , the regression coefficients in Table 6 control for the independent effects of

Table 5

Statistical distributions of regression variables and bivariate correlations with cycling share

\begin{tabular}{lllllll}
\hline Variable & Range & Mean & Median & SD & Cases & $\begin{array}{c}\text { Bivariate correlation } \\
\text { with cycling }\end{array}$ \\
\hline Bike share of work trips & $0.1-2.0$ & 0.5 & 0.3 & 0.5 & 64 & - \\
Gas price per liter in US \$ & $0.3-0.6$ & 0.4 & 0.4 & 0.1 & 64 & $+0.466^{* *}$ \\
Cars per person & $0.1-1.2$ & 0.7 & 0.8 & 0.2 & 64 & $-0.322^{* *}$ \\
Precipitation in cm & $1.4-19.2$ & 7.6 & 8.6 & 3.8 & 64 & $-0.424^{* *}$ \\
Cycling fatality rate & $0.0-2.4$ & 0.6 & 12.8 & 3.5 & 60 & $-0.422^{* *}$ \\
Distance of work trip in km & $2.0-16.2$ & 11.6 & 10.4 & 4.9 & 63 & $-0.536^{* *}$ \\
Temperature in degrees C & $-3.2-20.7$ & 10.3 & n.a. & n.a. & 64 & -0.027 \\
US-Canada dummy & $0-1$ & n.a. & & & & $-0.574^{* *}$ \\
\hline
\end{tabular}

** Significant at the $99 \%$ level. 
Table 6

Multiple regression analysis of bike mode share in Canadian provinces and American states, 2000/2001

\begin{tabular}{lll}
\hline \multicolumn{2}{l}{ Dependent variable: percentage of work trips by bike } & \\
\hline Explanatory variables & Model 1 & Model 2 \\
\hline Constant & 0.275 & 0.368 \\
& $(0.764)$ & $(0.765)$ \\
Policy variables & & \\
Gasoline price per liter in US \$ & $3.040^{* *}$ & $2.351^{*}$ \\
& $(1.159)$ & $(1.295)$ \\
Cycling fatality rate & $-0.151^{* *}$ & $-0.145^{* *}$ \\
& $(0.061)$ & $(0.061)$ \\
Urban structure and car availability & & -0.004 \\
Median work trip distance (km) & $-0.029 *$ & $(0.026)$ \\
Car availability $($ Cars per person) & $(0.016)$ & -0.225 \\
Weather variables & -0.463 & $(0.361)$ \\
Precipitation $(\mathrm{cm})$ & $(0.300)$ & $-0.047^{* *}$ \\
Temperature $\left({ }^{\circ} \mathrm{C}\right)$ & & $(0.011)$ \\
Culture & $-0.049^{* *}$ & $0.016^{*}$ \\
US-Canada dummy (US $=1$, Canada $=0)$ & & $(0.009)$ \\
Adjusted $R$ square & $(0.011)$ & -0.338 \\
$F-S t a t i s t i c$ & $0.019 * *$ & $(0.287)$ \\
\hline
\end{tabular}

Observations $=59 ;$ Standard errors in parentheses; $*$ Statistically significant at $90 \%$ level; **Statistically significant at $95 \%$ level.

each variable, holding the influence of the other variables constant.

All of the variables have the expected signs, but not all are statistically significant, possibly due to multicollinearity among some of the variables. Among the most significant variables are gasoline price and the cycling fatality rate. Model 1 indicates, for example, that an increase of ten cents per liter in gasoline price leads to a 0.3 percentage point increase in the bike share of work trips, while for every additional cyclist killed per 100,000 cyclists, the bike share falls by 0.15 percentage points. Those are considerable impacts, since they are relative to a mean cycling share of 0.52 and a median share of 0.30 , as shown in Table 5. As expected, both the distance of the work trip and car ownership are negatively associated with cycling, indicating that the longer the average work trip and the higher the level of car ownership in a state or province, the lower the bike share of work trips. Only the coefficient for trip distance is statistically significant, however. It indicates, for example, that an additional kilometer in work trip length is associated with a bike share that is 0.029 percentage points lower. The coefficient associated with cars per capita is negative, as expected, suggesting that the higher the car ownership in a state or province, the lower the share of cycling. Although not statistically significant, it would predict a fall of 0.46 percentage points in bike share for every additional car per capita, or a fall of 0.05 for every additional car per ten persons. Both weather variables are statistically significant and in the expected direction, suggesting less cycling where it is either cold or rainy.

Model 2 is the same as Model 1 but includes an additional variable to capture whatever other differences between Canada and the United States, we were not able to isolate explicitly in the first six explanatory variables. That might, for example, involve differences in bicycling policies, transit availability, crime, and culture. The US-Canada dummy variable is not statistically significant, and adds very little to the overall explanatory power of the equation. Nevertheless, the estimated coefficient has the expected negative sign, suggesting that, when the other six explanatory variables are taken into account (all of which are designed to capture Canadian-American differences), an American state is likely to have a bike share that is 0.34 percentage points lower than a Canadian province. That is a considerable impact, but the relatively large standard error (.287) renders the coefficient statistically significant only at the $75 \%$ level.

As in most multiple regression analysis, we cannot claim proof of causality. That is especially true with such aggregate state and provincial data, which mask large variations among cities and towns. At the very least, however, our estimated equations are consistent with the hypothesized impacts of the explanatory variables on the share of bike trips in each state and province. Without exception, all the coefficients have the expected signs and most are statistically significant. None of the three standard tests for multicolinearity (Tolerance, Variance Inflation Factor, and Condition Index) indicate any serious multicolinearity problems for the overall equations. Nevertheless, there are high bivariate correlations between the US-Canada dummy and gasoline price $(+.854)$, median work trip distance $(-.739)$, and cars per capita $(+.554)$, since there are large differences between the two countries on each of these three variables. Thus, when the dummy variable is added in Model 2, the estimated coefficients for gasoline price, trip distance, and cars per capita fall sharply, suggesting that the Canada-USA dummy siphons off some of their statistical relationship with bike share. Since the dummy variable adds little to the explanatory power of the overall equation while distorting the coefficients of three key variables, we prefer Model 1, which excludes the dummy.

Some might argue that it would be theoretically preferable to specify the dependent variable as the natural $\log$ of the odds of cycling (bike share/(1-bike share)) instead of our choice of a simple linear regression of the absolute share of bike trips. Such a 'log of odds' transformation would ensure that any predicted values from the estimated regression equation would thus be forced to lie between zero and one, the bounds of actual possible values of the bike share of trips. Table 7 presents the same two regression models as shown in Table 6 , but with the dependent variable transformed to be the natural $\log$ of (bike share/(1-bike share)). The alternative 'log of odds' specifications yield results very similar to those of the regressions in Table 6 . The sizes of the estimated variable coefficients obviously change, since the values for the dependent variable are greatly altered by the natural log 
transformation. Nevertheless, most individual explanatory variables have the same sign and roughly the same statistical significance in both the simple linear and natural $\log$ versions of the model. Moreover, the overall regression equations remain highly statistically significant regardless of type of specification, explaining almost two-thirds of the variation in the dependent variable.

Unfortunately, whatever the theoretical statistical advantages of the 'log of odds' regression equations, their coefficients are virtually impossible to interpret for practical policy purposes, as we were easily able to do with the first set of regression equations shown in Table 6. Furthermore, our regression analysis is only intended to help explain the differences in the current levels of cycling among Canadian provinces and American states. Our regressions are not intended for predicting alternative cycling levels that would result from different values of the explanatory variables. Thus, the 'log of odds' transformation seems unnecessary. We prefer the specifications shown in Table 6, and in particular the equation without the Canada-USA dummy variable. At any rate, the refined statistical specifications in Table 7 generally confirm the overall validity of our initial equation estimates in Table 6.

Data limitations made it impossible to test in this regression the impacts of individual policies specifically designed to promote cycling. Unlike the city data collected by Baltes (1997) and Dill and Carr (2003), there are no state

Table 7

Multiple regression analysis of log of odds of bike mode share in Canadian provinces and American states, 2000/2001

\begin{tabular}{lll}
\hline \multicolumn{2}{l}{ Dependent variable: ln (bike share/(1-bike share) } & \\
\hline Explanatory variables & Model 1 & Model 2 \\
\hline Constant & -7.869 & -7.789 \\
& $(1.373)$ & $(1.389)$ \\
Policy variables & & \\
Gasoline price per liter in US \$ & $8.430^{* *}$ & $7.832^{* *}$ \\
& $(2.083)$ & $(2.352)$ \\
Cycling fatality rate & $-0.441^{* *}$ & $-0.436^{* *}$ \\
& $(0.109)$ & $(0.110)$ \\
Urban structure and car availability & -0.015 & 0.006 \\
Median work trip distance (km) & $(0.028)$ & $(0.047)$ \\
& -0.186 & 0.21 \\
Car availability (cars per person) & $(0.539)$ & $(0.656)$ \\
& & \\
Weather variables & $-0.087 * *$ & $-0.085^{* *}$ \\
Precipitation $(\mathrm{cm})$ & $(0.019)$ & $(0.019)$ \\
Temperature $\left({ }^{\circ} \mathrm{C}\right)$ & 0.019 & 0.016 \\
& $(0.016)$ & $(0.017)$ \\
Culture & & -0.293 \\
US-Canada dummy (US $=1$, Canada $=0)$ & & $(0.522)$ \\
Adjusted $R$ square & & 0.650 \\
$F$-statistic & 0.655 & $0.000^{* *}$ \\
\hline
\end{tabular}

Observations $=59$; standard errors in parentheses; $* *$ statistically significant at 95\% level; *statistically significant at $90 \%$ level. Sources: Statistics Canada (2003) and US Census Bureau (2003). or provincial data available on total bike facilities. While state-level data on federal funding for bike and pedestrian facilities (combined) are available for the United States, federal funding in Canada was zero in 2001, making such a variable exactly equivalent to the USA-Canada dummy variable. At least two indirect policy variables appear to have a particularly strong relationship with cycling levels: gasoline price and the cycling fatality rate. While not proving causality, our regression results are consistent with the hypothesis that higher gasoline prices encourage cycling (by discouraging car use) and that cycling safety is crucial to increasing cycling levels.

\section{Conclusions and policy implications}

There is no simple answer to the question posed in the title of this article. Many factors help explain why Canadians cycle more than Americans. The denser, mixed-use development in Canadian cities leads to average trip distances those are only half as long in Canada and thus more bikeable than the longer trips Americans make. In addition, the costs of owning and driving a car are considerably higher in Canada than in the United States, while average incomes in Canada are lower. Both factors make cars less affordable in Canada and favor alternatives such as transit, walking, and cycling. Canadian cities have done more than American cities to facilitate cycling by providing bike paths and lanes, traffic-calmed neighborhoods, and ample bike parking. Moreover, safer cycling in Canada probably encourages more cycling there. Canada's better safety record might be attributable to more extensive training courses, more extensive cycling facilities, stricter police enforcement of traffic regulations, or more considerate driving behavior of motorists in Canada.

While Canada has done a better job than the United States promoting cycling and making it safer, both countries lag far behind Western Europe, where the bike share of travel averages about $5-10 \%$ of urban trips, but reaches highs of $20 \%$ in Denmark and 32\% in the Netherlands (Pucher and Dijkstra, 2000). Cycling is an integral part of the urban transport system in most Western European countries, a sharp contrast to North America, where it is a distinctly marginal mode.

The much higher levels of cycling in Europe are not simply historical artifacts or culturally determined. Indeed, most Western European countries dramatically shifted their urban transport policies in the 1970s to curb car travel and promote transit, walking, and cycling as the socially and environmentally friendly means of travel (European Conference of the Ministers of Transport, 2003 and 2004). Those European policies are the same kinds of policies that explain the higher level of cycling in Canada compared to the United States, but European countries have pursued them to a greater extent (Pucher and Dijkstra, 2000).

In terms of policy 'sticks', Europe has stricter land use policies, leading to higher urban densities and more mixed-use development than Canada, which in turn, has stricter land use 
policies, higher urban densities, and more mixed-use development than the United States. The result is average trip distances that are shorter and more bikeable in Europe than in Canada, which in turn has trips only half as long as in the United States. Policies restricting car use and raising its costs follow the same pattern. Thus, gasoline prices in Western Europe are about three times as high as in the United States and about twice as high as in Canada, with the price differential almost entirely due to taxation. Motor vehicle taxes and registration fees are also much higher in Europe than in either Canada or the United States. Driver licensing is both more stringent and more expensive in Europe. While Canadian cities have less parking and more restrictions on car use than American cities, European cities have far less car parking than Canadian cities. Many European cities have comprehensively traffic-calmed residential neighborhoods and have made large parts of their city centers entirely car-free.

In terms of policy 'carrots', bicycling infrastructure in Western Europe is more extensive and better integrated than in Canada and far superior to cycling facilities in American cities. Cycling facilities in Europe are also much better integrated with public transport. Cycling education is also a factor. In Germany, the Netherlands, and Denmark all school children benefit from mandatory training in safe cycling by the third or fourth grade. Indeed, they must pass a police-administered test to show that they can cycle safely, since most children cycle or walk to school. A few Canadian provinces have supported cycling and walking safety programs in their schools, but none have made it mandatory, and the programs are not nearly as intensive as in Europe.

The main conclusion we draw is that such land-use and transport policy differences are crucial for explaining the very different levels of cycling in the United States, Canada, and Europe. Perhaps the biggest obstacle for increasing cycling in North America is the political infeasibility of using any of the really effective policy 'sticks' that deter car use in Europe. For example, it is inconceivable that politicians anywhere in North America would be willing to raise gasoline taxes to European levels. Similarly, car-free city centers and comprehensive traffic calming of residential neighborhoods are not feasible options. Perhaps most ominous, low-density car-dependent suburban sprawl continues to spread out around every American city, and as shown by Miron (2003) and Filion et al. (2004), increasingly around Canadian cities as well. While central cities have been fairly successful at promoting cycling, their suburban counterparts have done little, and the longer trip distances on the suburban fringe make cycling less practical anyway.

While the bike share of work trips is three times higher in Canada than in USA, it is still only about one percent of trips, a very small share indeed. Thus, cycling remains a marginal mode of travel in both countries. A lot can and has been done in terms of 'carrot' measures to encourage cycling: more bike paths and lanes, better bike parking, cycling education and promotional programs. After two decades of such 'carrot' policies, however, the bike share of travel remains low. Given political constraints that prevent adoption of car-restrictive policy 'sticks', it seems likely that cycling will remain a marginal mode in North America, limited mostly to recreational activities and not for practical transport.

\section{Acknowledgements}

The authors would like to thank their colleagues David Hensher, Michael Greenberg, Martin Wachs, Joseph Seneca, Peter Stopher, John Rose, Radha Jagannathan, Todd Littman, and John Preston for their advice and suggestions for improving earlier versions of this article.

\section{References}

American Aeutomobile Association, 2005. Your Driving Costs. AAA. Washington, DC: Accessible at: www.ouraaa.com/news/library/drivingcost/index.html

Baltes, M., 1997. Factors influencing nondiscretionary work trips by bicycle determined from 1990 US census metropolitan area statistical area data. Transportation Research Record 1538, 96-101.

Canadian Automobile Association, 2005. Driving Costs. CAA. Ottawa, Canada Accessible at: www.caa.ca/e/automotive/driving-costs.shtml.

Canadian Petroleum Products Institute (CPPI), 2001. Fuel facts: gasoline price monitor. Prepared by Purvin \& Gertz, Inc. and MJ Ervin and Associates, Calgary, Canada. Available online at: www.centreforenergy.com.

Cervero, R., 1986. Urban transit in Canada: integration and innovation at its best. Transportation Quarterly 40 (3), 293-316.

Cervero, R., 1998. The Transit Metropolis: A Global Inquiry. Island Press, Washington, DC.

Clarke, A., 2003. Green modes and US transport policy: TEA-21. In: Tolley, R. (Ed.), Sustainable Transport: Planning for Walking and Cycling in Urban Environments. Woodhead Publishing, Cambridge, UK.

Dill, J., Carr, T., 2003. Bicycle commuting and facilities in major US cities: if you build them, commuters will use them-another look. Transportation Research Record 1828, 116-123.

Energy Information Administration (EIA), 2000. Petroleum Marketing Annual 2000. Washington, DC. Accessible online at: www.eia.doe.gov/pub/ oil_gas/petroleum/data_publications/petroleum_marketing_annual/historical/2000/pma_2000.html

Environment Canada, 2005. National Climate Data and Information Archive: Climate Data Online. Downsview, Ontario, Canada: Environment Canada. Accessible at: climate.weatheroffice.ec.gc.ca/

European Conference of the Ministers of Transport, 2003.Anon., 2003. Fifty Years of Transport Policy: Successes, Failures, and New Challenges. Organisation for Economic Cooperation and Development, Paris, France.

European Conference of the Ministers of Transport, 2004.Anon., 2004. Implementing Sustainable Urban Travel Policies: National Policies to Promote Cycling. Organisation for Economic Cooperation and Development, Paris, France.

European Union, 2003. Energy and transport in figures. Brussels, Belgium: European Commission, Directorate General for Energy and Transport. Accessible on-line at: europa.eu.int/comm/dgs/energy_transport/figures/ pocketbook/

Filion, P., Bunting, T., McSpurren, K., Tse, A., 2004. Canada-U.S. metropolitan density patterns: zonal convergence and divergence. Urban Geography 25 (1), 42-65.

Goldberg, M., Mercer, J., 1986. The Myth of the North American City: Continentalism Challenged. University of British Columbia Press, Vancouver, Canada.

Grant, J., 2002. Mixed use in theory and practice: canadian experience with implementing a planning principle. Journal of the American Planning Association 68 (1), 71-85.

International Energy Agency, 2005.Anon., 2005. Energy Prices and Taxes. Organisation for Economic Cooperation and Development, Paris, France. 
Jacobsen, P., 2003. Safety in numbers: more walkers and bicyclists, safer walking and bicycling. Injury Prevention 9, 205-209.

Kenworthy, J. 2002. Energy use in urban transport systems: a global review. Paper presented at the Third Biennial Conference on Advances in Energy Studies, Porto Venere, Italy.

League of American Bicyclists, 2005. Bicycling Friendly Communities. Washington, DC: author. Accessible at: www.bicyclefriendlycommunity. org/2003list.htm.

Miron, J., 2003. Urban Sprawl in Canada and America: Just How Dissimilar?. University of Toronto, Department of Geography, Toronto.

National Center for Walking and Bicycling, 2005. National Walking and Bicycling Study: Case Studies. Washington, DC: U.S. Department of Transportation. Accessible at: www.bikewalk.org/technical_assistance/ case_studies.htm

National Center for Walking and Bicycling, 2005. Bicycling Facilities Reference Guide. Washington, DC: U.S. Department of Transportation. Accessible at: www.bikewalk.org/bicycling/design_guide/bike_design_guide_index.htm

National Climatic Data Center (NCDC), 2005. US Climate Normals: Area Weighted State, Regional, and National Temperature and Precipitation. Washhington DC: U.S. Department of Commerce. Accessible at: www. ncdc.noaa.gov/oa/ncdc.html.

Nelson, A., Allen, D., 1997. If you build them, commuters will use them. Transportation Research Record 1578, 79-83.

Newman, P., Kenworthy, J., 1999. Sustainability and Cities: Overcoming Automobile Dependence. Island Press, Washington, DC.

Organisation for Economic Cooperation and Development, 2005a. National Accounts of OECD Countries. Paris, France: OECD. Accessible at: www. oecd.org.

Organisation for Economic Cooperation and Development, 2005b. International Road Traffic Accident Database. Paris, France: OECD. Maintained for OECD by the Bundesanstalt fuer Strassenwesen, Bergisch-Gladbach, Germany. Accessible on-line at: www.bast.de/htdocs/fachthemen/irtad/

Pucher, J., 1994. Canadian public transport: recent developments and comparisons with the United States. Transportation Quarterly 48 (1), 6578.

Pucher, J., Buehler, R., 2005. Cycling trends and policies in Canadian cities. World Transport Policy and Practice 11 (1), 43-61.

Pucher, J., Dijkstra, L., 2000. Making walking and cycling safer: lessons from Europe. Transportation Quarterly 54 (3), 25-50.

Pucher, J., Dijkstra, L., 2003. Promoting safe walking and cycling to improve public health: lessons from the Netherlands and Germany. American Journal of Public Health 93 (9), 1509-1516.

Pucher, J., Lefevre, C., 1996. Urban Transport Crisis in Europe and North America. Macmillan Press, London, UK.

Pucher, J., Renne, J., 2004. Socioeconomic characteristics of urban travelers: evidence from the 2001 NHTS. Transportation Quarterly 57 (3), 49-78.

Pucher, J., Komanoff, C., Schimek, P., 1999. Bicycling renaissance in North America? Recent trends and alternative policies to promote bicycling. Transportation Research A 33 (7/8), 625-654.

Shoup, D., 1999. Instead of free parking. Access 15 (2), 6-9.

Statistics Canada, 2003.Anon., 2003. Where Canadians Work and How They Get There. Statistics Canada, Ottawa, Canada.

Statistics Canada, 2005. Canadian Vehicle Survey: Number of vehicles in scope, by type of vehicle, province and territory (Table 405-0006). Ottawa, Canada: Statistics Canada. Accessible online at: www.statcan.ca.
Thunderhead Alliance and Chicagoland Bicycle Federation, 2004. Bicycle benchmarking project. Chicago: Authors.

Transport Canada, 2003. Urban Transportation Showcase Program. Ottawa, Canada: Transport Canada. Accessible at: www.tc.gc.ca/programs/environment/utsp/menu.htm

Transport Canada, 2004.Anon., 2004. Traffic Accident Information Database. Transport Canada, Ottawa, Canada.

Transportation Research Board, 2001.Anon., 2001. Making Transit Work: Insights from Western Europe, Canada, and the United States. National Academy Press, Washington, DC.

Transports Quebec, 2004. Provincial Assistance Programs for La Route Verte. Quebec, Canada: Ministere des Transports du Quebec. Accessible at: www. mtq.gouv.qc.ca/en/services/programmes/c6.asp.

Transports Quebec, 2004. Reseau routiers-amenagements cyclables: Politique sur le velo. Quebec City, Canada: Ministere des Transports du Quebec. Accessible at: www.mtq.gouv.qc.ca/fr/reseau/velo/politique.

U.S. Census Bureau, 2003. American Fact Finder: 2000 Decennial Census, Journey to Work. Washington, DC: U.S. Department of Commerce. Accessible at: factfinder.census.gov.

U.S. Department of Transportation, 1990.Anon., 1990. Moving America: National Transportation Policy. USDOT, Washington, DC.

U.S. Department of Transportation, 1994.Anon., 1994. The National Bicycling and Walking Study: Transportation Choices for a Changing America. Federal Highway Administration, Washington, DC.

U.S. Department of Transportation, 2000.Anon., 2000. Design Guidance Accommodating Bicycle and Pedestrian Travel: A Recommended Approach. Federal Highway Administration, Washington, DC.

U.S. Department of Transportation, 2003. National Household Travel Survey. Washington, DC: Federal Highway Administration. Accessible on-line at: nhts.ornl.gov/2001/index.shtml

U.S. Department of Transportation, 2004. National bicycling and walking study: Ten-year status report, October 2004. Washington, DC: Federal Highway Administration. Accessible at: www.fhwa.dot.gov/environment/ bikeped/study/index.htm

U.S. Department of Transportation, 2004b.Anon., 2004. Highway Statistics 2002. Federal Highway Administration, Washington, DC.

U.S. Department of Transportation, 2004. Federal-Aid Highway Program Funding for Pedestrian and Bicycle Facilities and Programs. Washington, DC: Federal Highway Administration. Accessible at: /www.fhwa.dot.gov/ environment/bikeped/bipedfund.htm

U.S. Department of Transportation, 2005. Fatality analysis reporting system (FARS). Washington, DC: National Highway Traffic Safety Administration. Available on-line at: www-fars.nhtsa.dot.gov/

U.S. Department of Transportation, 2005. Highway Statistics 2003. Washington, DC: Federal Highway Administration. Accessible at: www. fhwa.dot.gov/policy/ohim/hs03/index.htm

Velo Quebec, 2003. Reseau Velo Metropolitain. vol. 6, No 1, 2003. Montreal, Canada: Velo Quebec.

Vuchic, V., 1999. Transportation for Livable Cities. Center for Urban Policy Research Press, New Brunswick, NJ.

Ward's Communications, 2004.Anon., 2004. Ward's Motor Vehicle Facts and Figs. 2004. Ward's Communications, Southfield, MI.

Wilkinson, B., Chauncey, B., 2003. Are we there Yet? Assessing the Performance of State Departments of Transportation on Accommodating Bicycles and Pedestrians. National Center for Bicycling and Walking, Washington, DC. 